\title{
Experimental Immune-Mediated Pancreatitis in Neonatally Thymectomized Mice Immunized with Carbonic Anhydrase II and Lactoferrin
}

\author{
Kazushige Uchida, Kazuichi Okazaki, Toshiki Nishi, Suguru Uose, Hiroshi Nakase, \\ Masaya Ohana, Yumi Matsushima, Katsuyuki Omori, and Tsutomu Chiba \\ Department of Gastroenterology and Endoscopic Medicine (KU, KO, TN, SU, HN, MO, YM, TC), Central Laboratory \\ (KO), Kyoto University Hospital, Kyoto, Japan
}

\begin{abstract}
SUMMARY: We previously reported that autoantibodies against carbonic anhydrase II and lactoferrin are frequently identified in patients with autoimmune-related pancreatitis. To clarify the role of carbonic anhydrase II and lactoferrin, we created animal models of autoimmune pancreatitis by immunizing neonatally thymectomized mice with carbonic anhydrase II and lactoferrin and also by transferring immunized spleen cells to nude mice. Neonatally thymectomized BALB/c mice were immunized with carbonic anhydrase II or lactoferrin followed by three booster injections ( $n=10$ in each group). We transferred whole, CD4+, or CD8+ spleen cells prepared from immunized neonatally thymectomized mice to nude mice ( $n=5$ in each group). Gene expression of IFN- $\gamma$ and IL-4 was investigated using semiquantitative reverse transcription-polymerase chain reaction. Terminal deoxynucleotidyl transferase-mediated dUTP-biotin nick end-labeling staining was used to examine apoptosis. In immunized neonatally thymectomized mice, the prevalence of inflammation was significantly higher in the pancreas. Inflammation was present in all mice receiving whole or CD4+ cells. There was no change in any of the mice receiving CD8+ cells or nonimmunized spleen cells. Carbonic anhydrase II or lactoferrin-immunized mice had apoptotic duct cells or acinar cells, respectively. Expression of the IFN- $\gamma$ gene was up-regulated in each group. Similar findings were observed in the salivary glands and liver. An immunologic mechanism against carbonic anhydrase II or lactoferrin is involved in the pathogenesis of these pancreatitis models, in which the effector cells are Th1-type CD4+ T cells. (Lab Invest 2002, 82:411-424).
\end{abstract}

$S^{\text {in }}$ ince Sarles et al $(1961,1965)$ reported a type of pancreatitis with hypergammaglobulinemia, sêveral investigators have suggested that an autoimmune mechanism is involved in some patients with pancreatitis. The term "autoimmune pancreatitis" (AIP) was recently proposed (Yoshida et al, 1995) for this type of pancreatitis. Patients with AIP often have other autoimmune diseases such as sialoadenitis (Horiuchi et al, 1998; Ito et al, 1997; Okazaki et al, 2000; Uchida et al, 2000; Wakabayashi et al, 1998), sclerosing cholangitis (Horiuchi et al, 1998; Ito et al, 1997; Okazaki et al, 2000; Wakabayashi et al, 1998), or diabetes mellitus (Ito et al, 1997; Okazaki et al, 2000). Therefore, the terms "autoimmune exocrinopathy" (Strand and Talal, 1979), "a syndrome complex" (Montefusco et al, 1984), or "dry gland syndrome" (Epstein et al, 1982) have been proposed for this disorder, which involves

Received October 18, 2001.

This study was supported by Grant-in-Aid for Scientific Research (Category) of Ministry of Culture and Science of Japan (09670543); Grant-in-Aid for Research for the Future Program from The Japan Society for Promotion of Science (JSPS-RFTF97100201); and Supporting Research Funds from The Japanese Foundation for Research and Promotion of Endoscopy (JFE-1997).

Address reprint requests to: Dr. Kazuichi Okazaki, Department of Gastroenterology and Endoscopic Medicine, Kyoto University Hospital, ShogoinKawaracho, Sakyo-ku, Kyoto City, Kyoto, 606-8305, Japan. E-mail: okak@kuhp.kyoto-u.ac.jp multiple exocrine organs. These observations suggest that there are common target antigens against systemic exocrine organs in this disease, including the pancreas, salivary glands, and bile ducts. Although the exact nature of such antigens remains unclear, some candidates have been proposed. We recently reported that autoantibodies against carbonic anhydrase II (CAII) and lactoferrin (LF), which are widely distributed in exocrine organs such as the pancreas, salivary glands, and bile ducts, are frequently detected in patients with AIP (Okazaki et al, 2000; Uchida et al, 2000). It remains unknown, however, whether autoimmunity to CA-II and LF has an important role in the development of AIP. Although there are some animal models of autoimmune exocrinopathy (Mustafa et al, 1998; Tsubata et al, 1996; Vallance et al, 1998), the target antigens of those models are unclear. The neonatally thymectomized ( $\mathrm{nTx}$ ) BALB/c mouse is a well-known model of autoimmune gastritis (AIG) (Katakai et al, 1999; Kojima and Prehn, 1981; Nishio et al, 1994; Sakaguchi et al, 1985). In this model, nTx removes CD4+CD25+ regulatory $T$ cells from the periphery (Asano et al, 1996; Itoh et al, 1999), which induces a hyperimmune state. Therefore, these mice might develop other organ-specific autoimmune diseases in addition to AIG. In the present study, we established animal models of immune-mediated pancreatitis associated with multi-organ exocrinopathy by immunizing nTx mice with CA-II or LF and transferring 
the immunized spleen cells to nude mice to determine the mechanisms underlying AIP.

\section{Results}

\section{Macroscopic Findings of the Exocrine Organs}

The body weight and gross appearance of mice immunized with CA-II or LF, or mice receiving transferred cells, were not different from those of the respective control mice. Macroscopically, ascites or adhesion in the peritoneal cavity was not observed in any group. There was no bleeding or macroscopic atrophy observed in any exocrine organ, including the pancreas, salivary glands, and liver.

The weight of the salivary glands of nTx mice immunized with CA-II or LF was significantly lower than that in the respective control groups $(0<0.05$; Table 1). The weight of the pancreas in $\mathrm{nTx}$ mice immunized with CA-II or LF was also lower than that in the other groups, although there was no significant difference between $\mathrm{nTx}$ mice immunized with each respective immunogen, $\mathrm{CA}-\mathrm{Il}$ and $\mathrm{LF}$, and those with BSA (Table 1).

Liver weight was not influenced by immunization with CA-II or LF. Moreover, lymphocytes transferred from mice immunized with CA-II or LF, or from nonimmunized mice did not affect the weight of any exocrine organs in the nude mice (data not shown).

\section{Blood Chemistry and Serologic Findings}

Serum amylase levels in the nTx mice immunized with CA-II or LF were significantly higher than those in the respective control groups (Table 1). Other biochemical data that might be suggestive of exocrine organ destruction, such as gamma-glutamyl transpeptidase, alanine aminotransferase, and glucose, were not different among the groups (data not shown).

Serum levels of anti-CA-II antibody were not significantly different among nTx mice, nTx mice immunized with BSA, and nTx mice immunized with CA-II, although they tended to be higher in nTx-mice immunized with CA-II (Table 2). Serum levels of anti-CA-II antibody in nude mice were not affected by transfer of whole spleen cells or CD4+.
Serum levels of anti-LF antibody in nTx mice immunized with LF were significantly elevated compared with the nonimmunized groups with LF. Moreover, serum levels of anti-LF antibodies in nude mice that received whole or CD4+ cells were also significantly higher than in the other groups (Table 2).

\section{Histopathologic Findings}

(I) Pancreas. Moderate inflammatory cells were observed mainly around the ducts in the pancreas of nTx mice immunized with CA-II (Fig. 1, b and c). All five nude mice that received whole spleen cells or CD4+ cells prepared from nTx-mice immunized with CA-II had inflammatory cells around the pancreatic duct and edematous changes in the periductal area (Fig. 1, d and e). On the other hand, in nTx mice immunized with LF, there was moderate inflammatory cell infiltration in the pancreatic acini around the duct (Fig. 2a). In the cell transfer experiment, all five nude mice that received whole spleen cells or CD4+ cells prepared from nTx mice immunized with LF had inflammation in the periductal area (Fig. 2, b and c).

On the other hand, there was no inflammation observed in any of the mice that received CD8+ cells from nTx mice immunized with CA-II (Fig. 1f) or LF (Fig. 2d), or whole spleen cells from nonimmunized $\mathrm{nTx}$ mice or immunized nTx mice that received BSA (data not shown). In the nTx mice immunized with CA-II or LF, nude mice receiving whole spleen cells and CD4 + spleen cells prepared from nTx-mice immunized with each antigen, the prevalence of inflammation and the inflammation scores of the exocrine pancreas were significantly higher than those in the respective control groups (Tables 3 and 4). The prevalence of insulitis was not influenced by immunization with CA-II or LF or lymphocyte transfer (Tables 3 and 4).

(II) Other Organs. In the salivary glands of nTx mice immunized with CA-II or LF, focal inflammation around the ducts was more prevalent than that in the respective control groups (Table 3). In the liver, cholangitis was observed in the nTx mice immunized with BSA and more prominently in the immunized mice compared with the nonimmunized mice. In the cell transfer

Table 1. Weight of Exocrine Organs and Serum Amylase Levels in Mice Immunized with CA-II or LF

\begin{tabular}{|c|c|c|c|c|c|c|c|}
\hline & $n$ & Salivary glands (wt $\%$ ) & & & Pancreas (wt\%) & Amylase (IU/I) & \\
\hline Non-nTx & 10 & $0.889 \pm 0.103$ & \multirow{8}{*}{\multicolumn{2}{|c|}{ * }} & $0.939 \pm 0.121$ & $6796.0 \pm 602.8$ & \multirow{8}{*}{ * } \\
\hline Non-nTx+BSA & 10 & $0.858 \pm 0.201$ & & & $0.946 \pm 0.221$ & $5923.6 \pm 613.2$ & \\
\hline Non-nTx+CA-II & 10 & $0.882 \pm 0.154$ & & & $0.972 \pm 0.144$ & $6336.7 \pm 411.7$ & \\
\hline Non-nTx+LF & 10 & $0.843 \pm 0.194$ & & & $0.995 \pm 0.192$ & $5806.7 \pm 221.2$ & \\
\hline $\mathrm{nTx}$ & 10 & $0.864 \pm 0.135$ & & & $0.950 \pm 0.119$ & $6033.0 \pm 767.1-$ & \\
\hline $\mathrm{nTx}+\mathrm{BSA}$ & 10 & $0.897 \pm 0.097$ & & & $0.849 \pm 0.151$ & $6636.7 \pm 663.3$ & \\
\hline $\mathrm{nTx}+\mathrm{CA}-\mathrm{II}$ & 10 & $0.556 \pm 0.081$ & & & $0.716 \pm 0.183$ & $8242.0 \pm 657.7$ & \\
\hline $\mathrm{nTx}+\mathrm{LF}$ & 10 & $0.466 \pm 0.171$ & & & $0.714 \pm 0.132$ & $8906.0 \pm 1207.0$ & \\
\hline
\end{tabular}

Non-nTx, nonimmunized non-nTx BALB/c mice; Non-nTx+CA-II, non-nTx mice immunized with CA-II; Non-nTx+LF, non-nTx mice immunized with LF; nTx, nonimmunized $n T x$ BALB/c mice; $n T x+B S A, n T x$ mice immunized with BSA; nTx +CA-II, nTx mice immunized with CA-II; nTx + LF, nTx mice immunized with LF; CA-II, carbonic anhydrase II; LF, lactoferrin.

Values are expressed as the percentage of body weight (wt\%). ${ }^{*} p<0.05$ vs control groups. 
Table 2. Serum Levels of Anti CA-II or LF Antibody

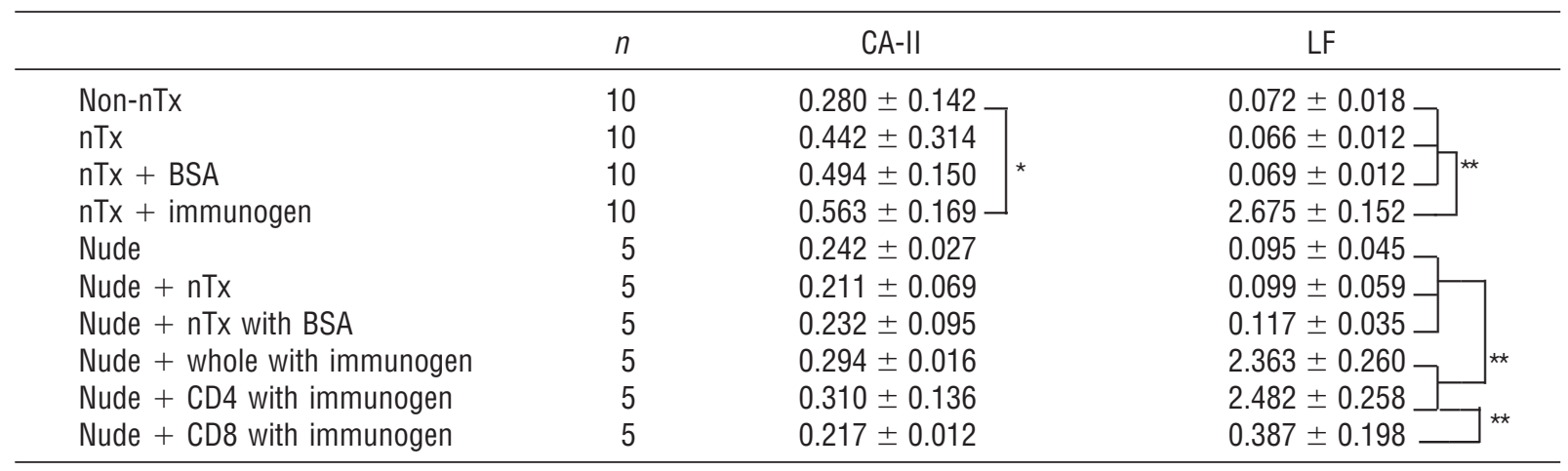

Non-nTx, nonimmunized non-nTx BALB/c mice; $n T x$, nonimmunized $n T x$ BALB/c mice; $n T x+B S A, n T x$ mice immunized with BSA; $n T x+$ immunogen, $n T x$ mice immunized with CA-II or LF; Nude, untreated nude mice; Nude + nTx, nude mice that received whole spleen cells prepared from nonimmunized nTx mice; Nude + $n T x$ with BSA, nude mice that received whole spleen cells prepared from $n T x$ mice immunized with BSA; Nude $+\mathrm{nTx}$ with immunogen, nude mice that received whole spleen cells from nTx mice immunized with CA-II or LF; Nude + CD4 with immunogen, nude mice that received $\mathrm{CD}^{+}$cells from nTx mice immunized with CA-II or LF; Nude + CD8 with immunogen, nude mice that received CD8 ${ }^{+}$cells from $\mathrm{nTx}$ mice immunized with CA-II or LF; CA-II, carbonic anhydrase II; LF, lactoferrin.

Values are absorbency at 0. D. $490 \mathrm{~nm} .{ }^{*} p<0.05$ vs non-nTx. ${ }^{* *} p<0.05$ vs control groups and nude + CD8 with LF.

experiment, all five nude mice, that received whole spleen cells or CD4+ cells prepared from nTx mice immunized with CA-II or LF, had inflammation around the bile duct and the salivary gland ducts (Figs. 3 and 4; Table 4). The prevalence and severity of AIG were not increased in the immunized mice or in the transfer mice (data not shown).

\section{Immunohistochemistry}

The majority of lymphocytes infiltrating into the pancreas in nTx mice immunized with CA-II or LF were CD4 + cells (Fig. 5). In contrast, only small numbers of CD8 + and B220+ cells were observed throughout the pancreas. The major infiltrating lymphocytes were also CD4+ $\mathrm{T}$ cells in the salivary glands and liver of the transferred nude mice (data not shown).

\section{In Situ End-Labeling of Fragmented DNA}

Cells positively stained using the terminal deoxynucleotidyl transferase-mediated dUTP-biotin nick endlabeling (TUNEL) method were observed mainly in the ductal cells of the pancreas of the nude mice that received $\mathrm{CD} 4+$ spleen cells from $\mathrm{nTx}$ mice immunized with CA-II (Fig. 6, a and b). In nude mice that received CD4+ spleen cells from nTx mice immunized with LF, the acinar cells of the pancreas stained positively using the TUNEL method (Fig. 6, c and d). nTx mice immunized with CA-II or LF and nude mice that received whole spleen cells prepared from nTx mice immunized with CA-II or LF had cells with TUNEL staining similar to that of nude mice that received CD4+ spleen cells from nTx mice immunized with CA-II or LF (data not shown). These findings indicate that there was cell-mediated destruction of exocrine organs by CD4+ cells.

\section{Gene Expression of Cytokines by Reverse Transcription-Polymerase Chain Reaction (RT-PCR)}

Gene expression of IFN- $\gamma$ was detected using RT$\mathrm{PCR}$ in the salivary glands of nonimmunized nTx mice,
nTx mice immunized with CA-II or LF, and nude mice that received whole or CD4+ spleen cells prepared from nTx mice immunized with CA-II or LF. IFN- $\gamma$ was not detected, however, in nude mice that received CD8 + cells or in non-nTx mice. Expression of the IL-4 gene was not detected in any of the mice (Fig. 7, a and b).

\section{Discussion}

Patients with AIP often have other autoimmune diseases, such as sialoadenitis (Horiuchi et al, 1998; Ito et al, 1997; Okazaki et al, 2000; Uchida et al, 2000; Wakabayashi et al, 1998), sclerosing cholangitis (Horiuchi et al, 1998; Ito et al, 1997; Okazaki et al, 2000; Wakabayashi et al, 1998), or diabetes mellitus (Ito et al, 1997; Okazaki et al, 2000), leading to the terms "autoimmune exocrinopathy" (Strand and Talal, 1979), "complex syndrome" (Montefusco et al, 1984), or "dry gland syndrome" (Epstein et al, 1982). The involvement of multiple exocrine organs suggests the existence of common target antigens in the systemic exocrine organs.

We previously reported that some patients with pancreatitis and Sjögren's syndrome have cellular and humoral immune responses against a $60-\mathrm{kDa}$ protein prepared using the monoclonal antibody SP3-1 (Okazaki et al, 1989) and CA-II (Kino-Ohsaki et al, 1996). We reported that autoantibodies against CA-II and LF are frequently identified in patients with AIP, and the prevalence of these two antibodies is independent (Okazaki et al, 2000; Uchida et al, 2000). These two proteins are similarly distributed in several exocrine organs, including the pancreas, salivary gland, liver (biliary tract), and kidney (renal tubule) (Colomb et al, 1976; Miyauchi, 1984; Okazaki et al, 1989). CA-II, a 38 $\mathrm{kDa}$ zinc binding protein, converts carbon dioxide to bicarbonate. In the pancreas, CA-II is located in the duct cells (Kumpulainen and Jalovaara, 1981). Two animal models of sialoadenitis (Nishimori et al, 1995) and cholangitis (Ueno et al, 1998) using different mouse strains immunized with CA-II were previously 

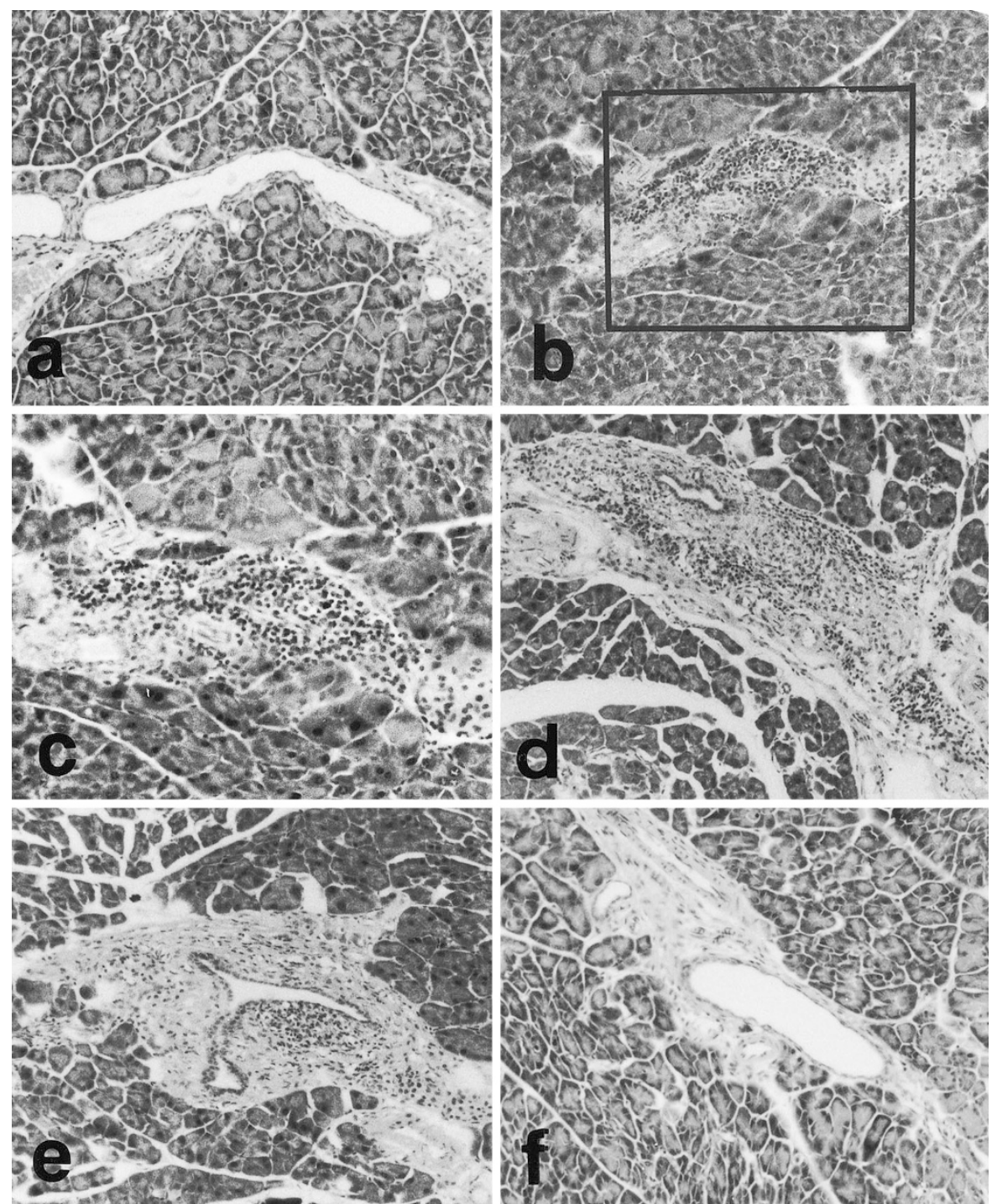

Figure 1.

Histopathology of the pancreas in the carbonic anhydrase II (CA-II) experiment. Hematoxylin and eosin-stained tissue sections from nonimmunized neonatal thymectomy (nTx) mice show no lymphocyte infiltration (a). In the $n T x$ mice immunized with CA-II (b and c), moderate lymphocyte infiltration and destruction of the small duct were observed. Lymphocyte infiltration with edematous changes was observed in the nude mice that received whole (d) or CD4+ (e) spleen cells from nTx mice immunized with CA-II. No inflammation was observed in any of the mice that received CD8 + cells (f). Original magnification, $\times 200$ (c) and $\times 100$ (a and $b ; d-f)$.

reported. Subcutaneous immunization with CA-II induced sialoadenitis in PL/J mice $\left(\mathrm{H}-2^{\mathrm{U}}\right)$ and SJL/JCr $\left(\mathrm{H}-2^{\mathrm{s}}\right)$ but not in other mouse strains $\left(\mathrm{H}-2^{\mathrm{p}}, \mathrm{H}-2^{\mathrm{q}}\right.$, and $\mathrm{H}-2^{2}$ )(Nishimori et al, 1995). On the other hand, intraperitoneal immunization of BALB/c mice $\left(\mathrm{H}-2^{\mathrm{d}}\right)$ and $\mathrm{DBA} / 1$ mice $\left(\mathrm{H}-2^{\mathrm{q}}\right)$ with $\mathrm{CA}-\mathrm{Il}$ induced cholangitis but not sialoadenitis (Ueno et al, 1998). These two models suggest that CA-II-induced sialoadenitis or cholangitis develops independently as a consequence of different strain susceptibility, major histocompatibility complex (MHC) haplotype, or immunization route. Although the effector cells for sialoadenitis in PL/J mice immunized with CA-II are unknown, the cholangitis model in BALB/c mice by Ueno et al (1998) suggests that CD4+ cells are the effector cells.

LF, a single chain $78 \mathrm{kDa}$ glycoprotein, has bacteriostatic activity (Ellison et al, 1988) as well as iron transporting capacity (Ainscough et al, 1979). It is rich in granulocytes and secretory fluid from the exocrine organs such as the mammary, lachrymal, and salivary glands (Miyauchi and Watanabe, 1987; Reitamo et al, 1980). LF is also detected in the normal bile duct (Saito and Nakanuma, 1992) and pancreatic acini (Colomb et al, 1976), although in very small amounts. On the other hand, immunohistochemical studies indicate that LF is strongly positive in the biliary epithelial cells in hepatolithiasis (Saito and Nakanuma, 1992), and the concentration of LF in pancreatic juice is increased in patients with chronic pancreatitis (Fedail et al, 1978; Hayakawa et al, 1983). Although the role of LF in cholangitis and pancreatitis is unknown, LF might be involved in the pathophysiology of inflammation in these organs. Moreover, it was recently reported that orally administered LF activates intestinal mucosal 


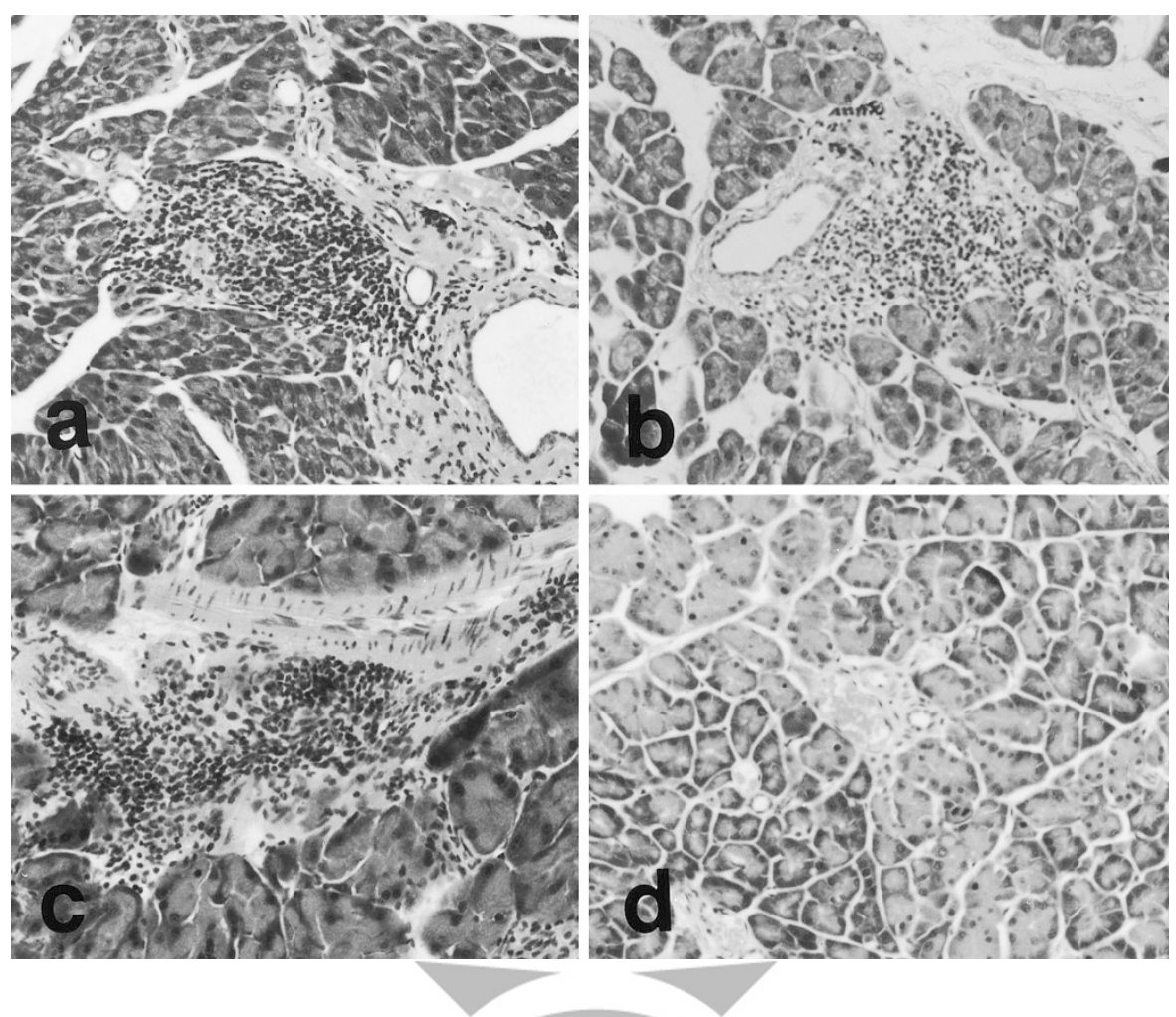

Figure 2.

Histopathology of the pancreas in the lactoferrin (LF) experiment. In the pancreas of nTx mice immunized with LF, there was moderate inflammatory cell infiltration in pancreatic acini around the duct (a). In the cell transfer experiment, all five nude mice that received whole spleen cells or CD4+ cells prepared from nTx mice immunized with LF had inflammation in the periductal area ( $b$ and $c)$. In contrast, there was no inflammation observed in any of the nude mice that received CD8+ cells (d). Original magnification, $\times 200(a-d)$.

immunity by increasing CD4+ and $\mathrm{CD} 8+\mathrm{T}$ cells, which suggests that LF also has potent immunomodulating or immunogenic activities (Brock, 1995). Indeed, LF is one target antigen recognized by perinuclear anti-neutrophil cytoplasmic antibodies (P-ANCA) and anti-LF antibodies are often detected in patients with primary sclerosing cholangitis and ulcerative colitis as well as AIP (Peen et al, 1996). We previously reported an antibody to LF in autoimmune liver diseases, particularly in patients with autoimmune cholangitis (Ohana et al, 1998). By itself, however, the presence of autoantibodies against CA-II or LF does not necessarily mean that these proteins are involved in the pathogenesis.

In the present study, we successfully developed immune-mediated pancreatitis using $\mathrm{nTx}$ BALB/c mice immunized with CA-II and LF, although it was not necessarily due to autoimmunity. Apart from antigenspecific immunity, mild cholangitis could be induced by control immunization with BSA or Freund's complete adjuvant (FCA) alone (data not shown). As inflammation in $\mathrm{nTx}$-mice immunized with CA-II or LF was more severe compared with controls, antigenspecific immunity might be involved in immunemediated cholangitis as well as in sialoadenitis and pancreatitis. The adoptively transferred BALB/c nu/nu mice spontaneously developed persistent inflammation in the same organs as the immunized nTx mice. $\mathrm{nTx}$ BALB/c mice spontaneously develop various organ-specific autoimmune diseases such as gastritis, thyroiditis, oophoritis, orchitis, and insulitis. Autoim- mune gastritis is induced in $60 \%$ of $n T x$ mice, whereas thyroiditis, sialoadenitis, or insulitis occur at a very low incidence. In the present models, the prevalence of pancreatitis, sialōadeñitis, annd cholangitis was drastically increased, whereas other lesions, such as AIG (data not shown) or insulitis, were not increased. Although we did not evaluate other strains in this study, several animal models of autoimmune disease using $\mathrm{nTx}$ mice showed that organ specific inflammation depends on strains such as sialoadenitis in NFS/ sld mice (Hayashi et al, 1996), hepatitis in A/J mice (Kamiyasu et al, 1997; Masanaga et al, 1998), and gastritis in BALB/c mice. To clarify the strain specificity in our models, further study using other strains is necessary.

In nTx BALB/c mice with AIG, the effector cells were reported to be CD4 + Th1 cells (Asano et al, 1996; Itoh et al, 1999; Katakai et al, 1999; Kojima and Prehn, 1981; Nishio et al, 1994; Sakaguchi et al, 1985). In general, the pathophysiology of autoimmune diseases usually depends on the interaction of self-antigenspecific $\mathrm{T}$ cells and regulatory $\mathrm{T}$ cells. Moreover, $\mathrm{nTx}$ depletes the CD4+ and CD25+ regulatory $T$ cells in the periphery (Asano et al, 1996; Itoh et al, 1999), which results in a hyperimmune state. Whole or CD4+ spleen cells prepared from nTx mice immunized with CA-II or LF induced persistent inflammation of the same organs in the syngenic nude mice as in those in the $\mathrm{nTx}$ mice immunized with the respective proteins, whereas CD8+ cells were never pathogenic. In the present models, we confirmed antigen-specific immu- 


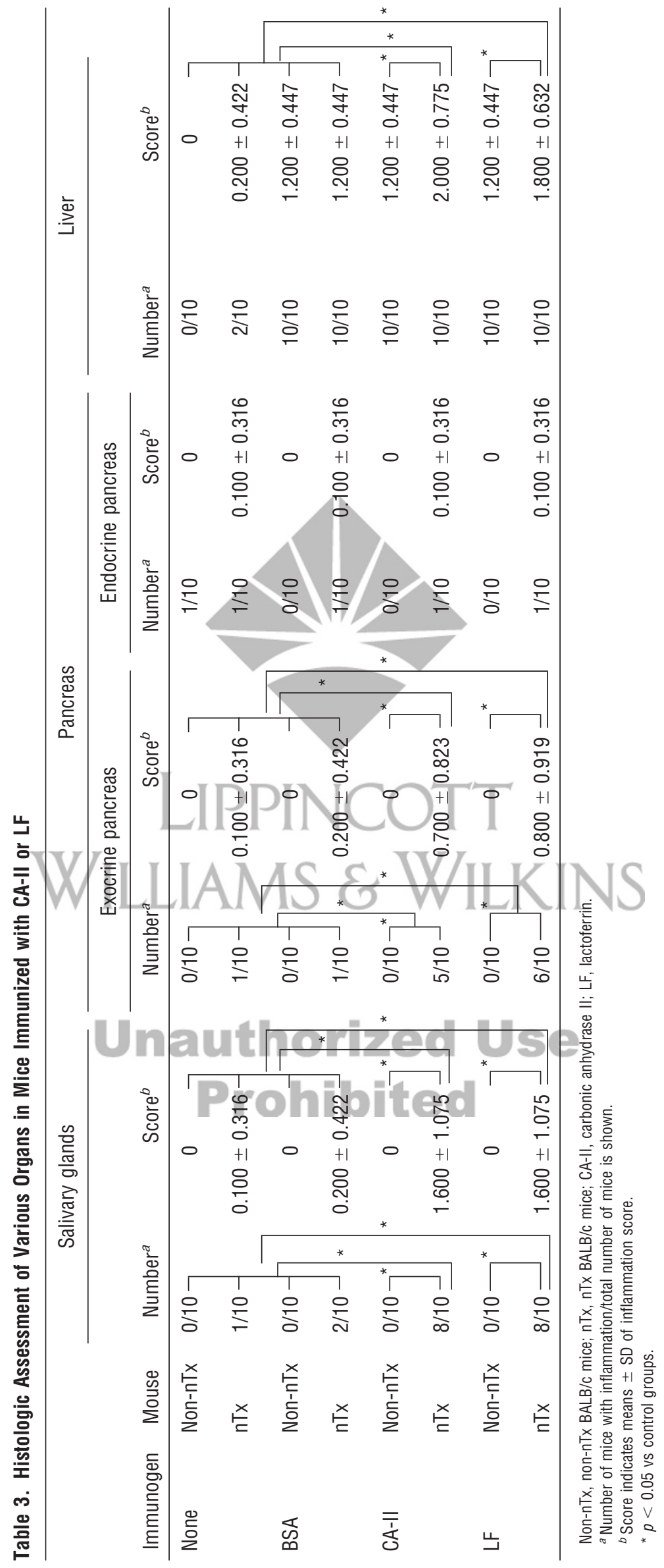




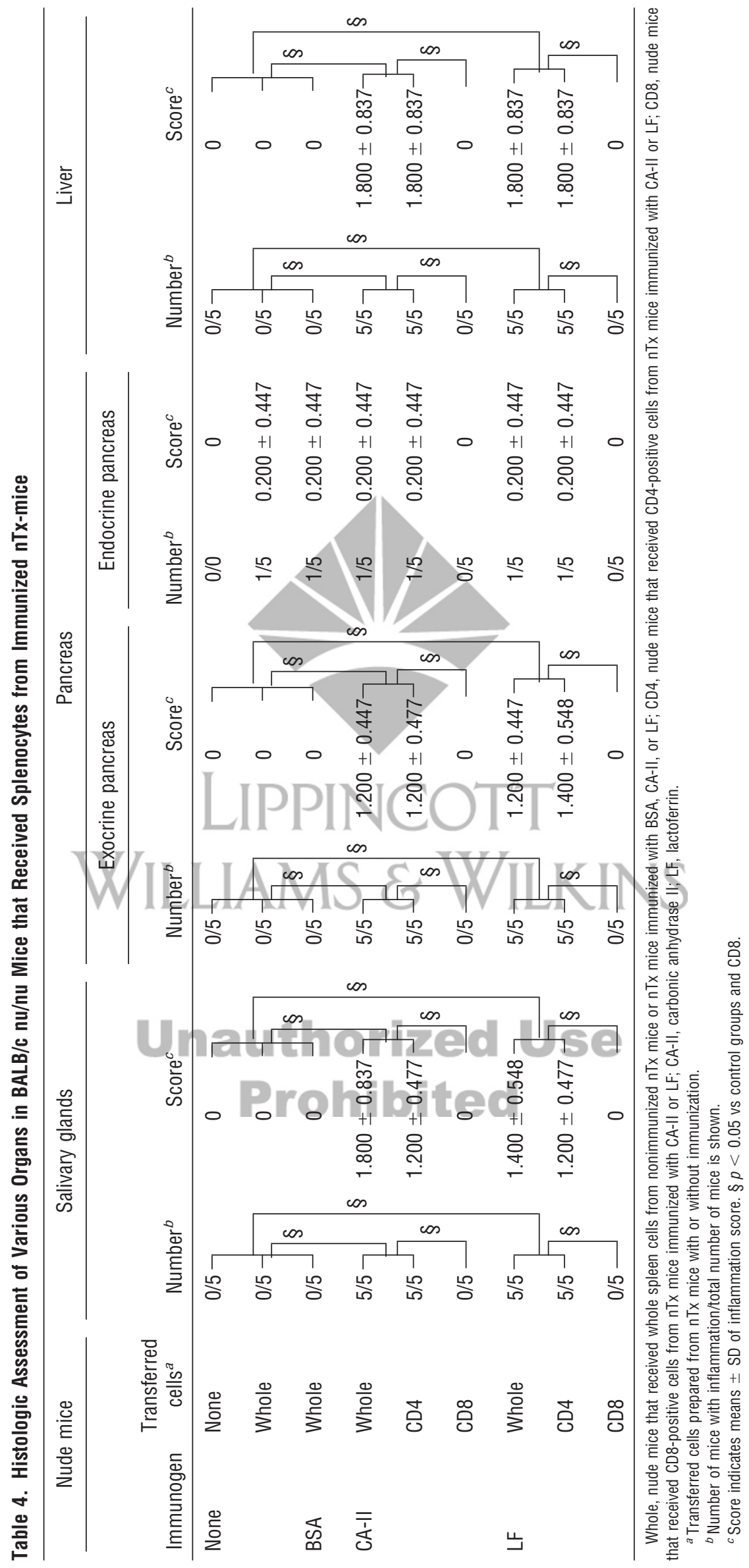



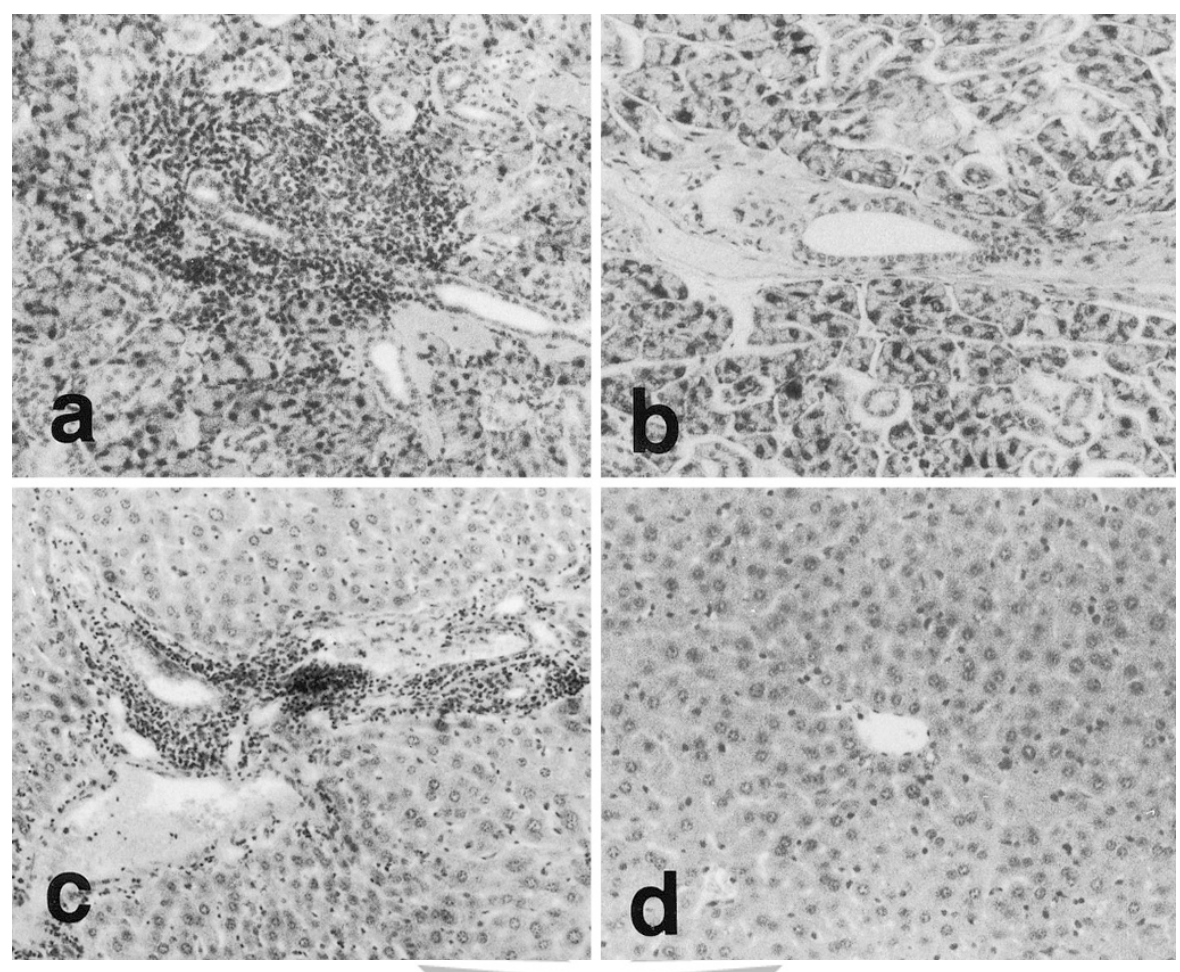

Figure 3.

Hematoxylin and eosin-stained section of salivary glands and liver tissue in the nude mice that received spleen cells sensitized with CA-II. In the salivary glands (a and b) and liver ( $c$ and d), inflammation around the draining duct was observed in nude mice that received CD4+ spleen cells prepared from nTx mice immunized with CA-II (a and c). On the other hand, there was no inflammation in the nude mice that received CD8 + cells from nTx mice immunized with CA-II (b and d). Original magnification, $\times 200$.

nity by increased cellular and humoral immune responses against CA-II or LF. These findings suggest that $\mathrm{MHC}$-class II restricted $\mathrm{CD} 4+\mathrm{T}$ cells react to CA-II or LF, which allows them to escape from negative selection in the thymus and depletion of regulatory $T$ cells such as CD4+CD25+ T cells in the periphery, and have important roles in the development of immune-mediated pancreatitis and exocrinopathy in nTx BALB/c mice. Moreover, in inflamed tissues, gene expression of IFN- $\gamma$, but not IL-4, was detected in both models, which suggests that a Th1-type of immune response predominates over the Th2-type. Th1-type CD4+ cells might be involved in patients with AIP (Okazaki et al, 2000) and Sjögren's syndrome (Fox et al, 1994). Thus, the microenvironment of the Th1/Th2 immune balance in nTx mice with exocrinopathy is similar to that in patients with AIP. Taken together, these results suggest autoimmune-mediated exocrinopathy against CA-II and LF as common target antigens.

Although the antigens involved are unknown, aly-/- mice and MRL/Ipr mice spontaneously develop pancreatitis in which the effector cells are also Th1-type CD4 + T cells (Mustafa et al, 1998; Tsubata et al, 1996). Recent observations also suggest a functional role of T lymphocytes, such as cytotoxicity (Hunger et al, 1997) or neuroimmune interactions in chronic pancreatitis (Keith et al, 1985). In mice with cerulein-induced experimental pancreatitis, CD4+ T cells are required for complete development of pancreatic lesions (Demols et al, 2000). Apart from auto- immunity, these CD4+ T cells probably induce the activation of macrophages and further proinflammatory reactions during the early stage of acute pancreatitis, as well às direct cytotoxicity effects through Fas ligand expression (Demols et al, 2000).

In the model of Sjögren's syndrome using nTx NFS/sld mice, Th1-type CD4+ T cells also play an important role in the development of sialoadenitis. In this model and human Sjögren's syndrome, $\alpha$-fodrin -seem to be involved as an autoantigen (Haneji et al, 1998; Hayashi et al, 1996). The homology of the amino acid sequences among $\alpha$-fodrin, CA-II, and LF is less than $10 \%$, which suggests that these three proteins are completely different and are not likely to be cross-reactive. After induction of organ specific inflammation by an autoantigen, immune responses against other antigens in the inflamed tissues are also induced (Peakman and Vergani, 1997). Therefore, we cannot rule out a possibility of secondary involvement of autoimmune responses against a-fodrin in our models. Further study including measurement of anti $\alpha$-fodrin antibody is needed.

There remains a possibility that CD $8+$ lymphocytes are also the effector cells, because CD8 $+T$ cells might be the effector cells in MHC class-II-deficient mice, which spontaneously develop pancreatitis (Vallance et al, 1998). Indeed, HLA-DR- and CD8+ cells also increased in the peripheral blood and infiltrated into pancreatic tissue in patients with AIP, although CD4 + cells predominated over CD8 + cells (Okazaki et al, 2000). TGF- $\beta$ is an important regulating factor in 


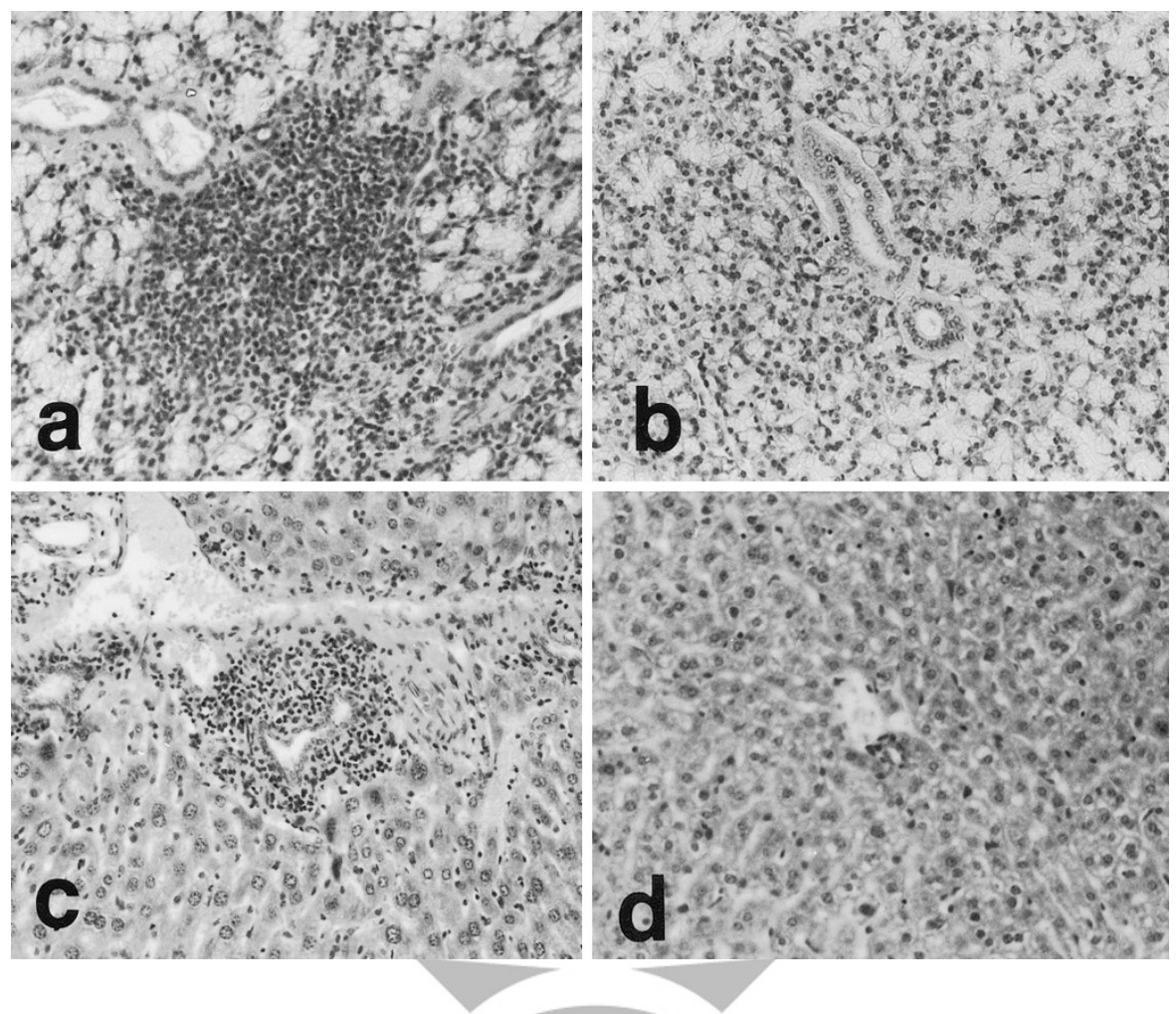

Figure 4.

Hematoxylin and eosin-stained section of salivary glands and liver tissue in nude mice that received spleen cells sensitized with LF. In nude mice that received CD4+ spleen cells prepared from $\mathrm{nTx}$ mice immunized with LF, there was inflammation around the draining duct of the salivary glands (a) and bile duct (c) inflammation. On the other hand, there was no inflammation in the nude mice that received CD8 + cells from nTx mice immunized with LF in salivary gland (b) and liver (d). Original magnification, $\times 200$.

the maintenance of immune homeostasis (Marth et al, 1996). Loss of TGF- $\beta$ signaling in TGF- $\beta$ dominant negative mutant mice might contribute to AIP (Hahm et al, 2000). TGF- $\beta$ gene expression in our mouse model was not different compared with control mice (data not shown).

In conclusion, an autoimmune mechanism against CA-II or LF via Th1-type CD4 + cells might be involved in the pathogenesis of AIP and associated exocrinopathy. Further studies, including identification of the antigenic motif in the amino acid sequence and of the genetic background that confers susceptibility, are necessary to clarify the precise mechanism.

\section{Materials and Methods}

\section{Mice and Immunization}

Male and female BALB/c CrSlc and BALB/c nu/nu CrSlc mice (Japan SLC, Shizuoka, Japan) were bred in the Facility of Experimental Animals at the Faculty of Medicine of Kyoto University, Kyoto, Japan, under specific pathogen-free conditions. nTx was performed in BALB/c CrSlc mice on the third day after birth under ether anesthesia, as described previously (Asano et al, 1996; Itoh et al, 1999; Katakai et al, 1999; Kojima and Prehn, 1981; Nishio et al, 1994; Sakaguchi et al, 1985). Bovine CA-II or LF (Sigma Chemical, St. Louis, Missouri) was used as an antigen for the immunization. In a preliminary study using Western immunoblotting, we confirmed that an extract of murine pancreas reacts with sera from animals immunized with bovine CA-II and LF (data not shown). nTx mice were injected with an emulsion of $0.1 \mathrm{mg}$ of CA-H or LF in $0.1 \mathrm{ml}$ PBS with $0.1 \mathrm{ml}$ FCA (Chemicon International Inc., Temecula, California) at three to four sites subcutaneously at 6 weeks of age and were killed after three booster injections at 2-week intervals. Control mice were immunized with $0.1 \mathrm{mg}$ of BSA (Sigma Chemical) in 0.1 $\mathrm{ml}$ of PBS and FCA. The mice were divided into eight groups ( $n=10$ in each group): normal BALB/c mice not immunized (non-nTx); normal mice immunized with BSA (non-nTx + BSA); nonimmunized nTx mice $(n T x)$; $n T x$ mice immunized with BSA (nTx + BSA); normal mice immunized with CA-II (non-nTx + CA-II); nTx mice immunized with CA-II (nTx + CA-II); normal mice immunized with LF (non-nTx + LF); and nTx mice immunized with LF (nTx + LF). The experimental procedures in this study were approved by the Animal Protection Committee of Kyoto University.

\section{Adoptive Transfer}

To clarify which cells are the effector cells for the development of exocrinopathy whole, CD4+, and CD8 + spleen cells $\left(1 \times 10^{6}\right)$ prepared from $\mathrm{nTx}$ mice immunized with CA-II or LF were transferred to 6-week-old BALB/c nu/nu (nude) mice. In control mice, spleen cells prepared from nTx mice immunized with BSA were transferred. Spleen cells prepared from $\mathrm{nTx}$ mice immunized with CA-II or LF were incubated 

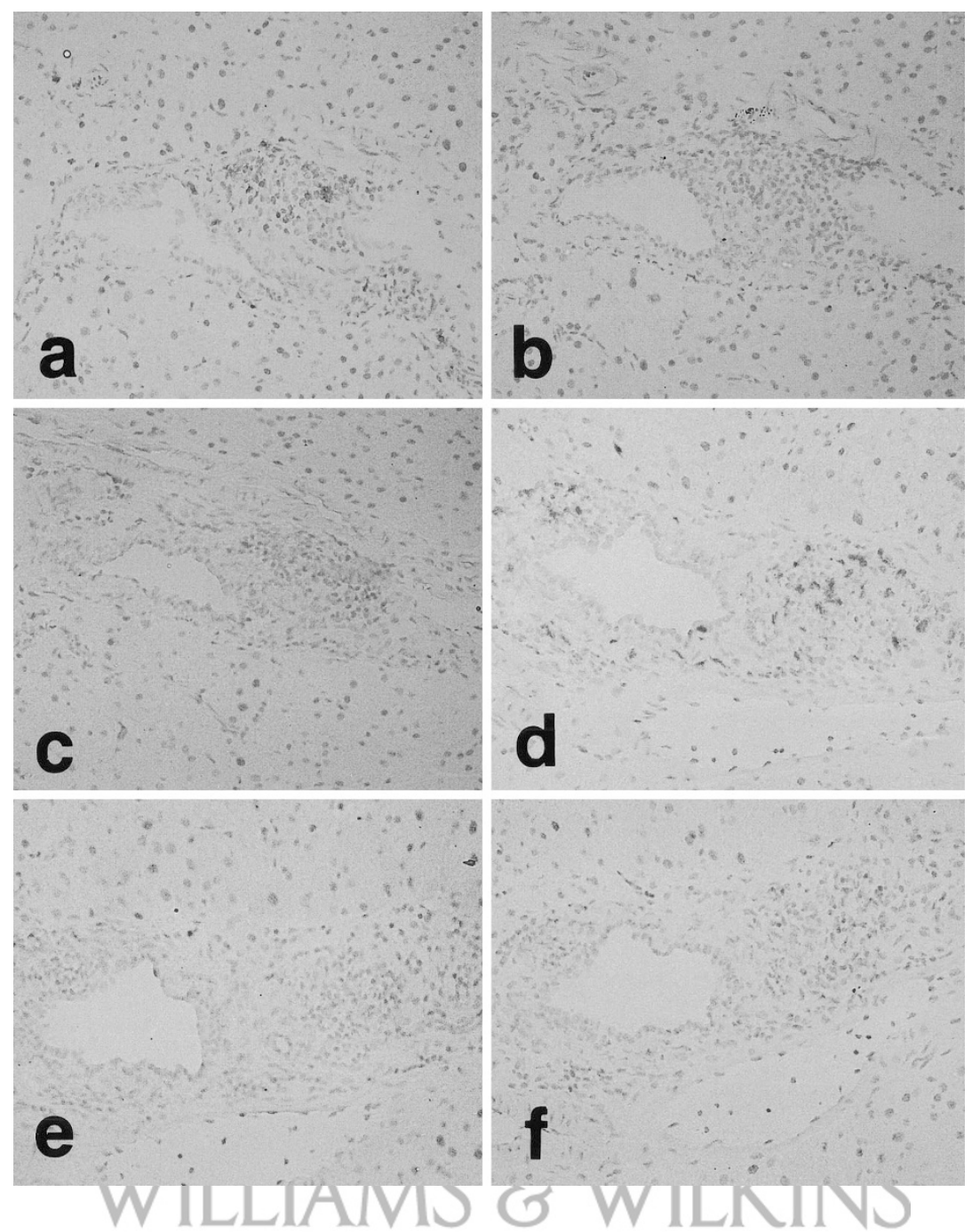

Figure 5.

Immunohistochemistry of the pancreas from $\mathrm{nTx}$ mice immunized with CA-II $(\mathrm{a}-\mathrm{c})$ or $\mathrm{LF}(\mathrm{d}-\mathrm{f})$. CD4+ cells predominantly infiltrated around the small duct (a and d). $C D 8+$ and B220 + cells were rarely observed in the serial sections ( $b$ and $c$; e and f). Original magnification, $\times 200$.

with phycoerythrin (PE)- or FITC-conjugated antimouse CD4 or CD8 (Coulter, Miami, Florida) at $4^{\circ} \mathrm{C}$ for 30 minutes. CD4+ or CD8+ cells were isolated by sorting FITC- or PE-labeled spleen cells with FACS Vantage (Becton \& Dickinson, Lincoln Park, New Jersey). We confirmed that these cells significantly responded to CA-II or LF using a ${ }^{3} \mathrm{H}$-thymidine proliferation assay (data not shown). In the transfer experiment, the mice were divided into nine groups ( $n$ $=5$ in each group): nontransferred BALB/c nu/nu mice (nude); nude mice receiving whole spleen cells from $\mathrm{nTx}$ mice without immunization (nude $+\mathrm{nTx}$ ); nude mice receiving whole spleen cells from $n T x$ mice immunized with BSA (nude + nTx with BSA); nude mice receiving whole spleen cells from $n T x$ mice immunized with CA-II (nude + nTx with CA-II); nude mice receiving CD4 + spleen cells from $\mathrm{nTx}$ mice immunized with CA-II (nude + CD4 with CA-II); nude mice receiving $C D 8+$ cells from immunized $n T x$ mice (nude + CD8 with CA-II); nude mice that received whole spleen cells from $n T x$ mice immunized with LF (nude + whole with LF); nude mice that received
CD4+ spleen cells from nTx mice immunized with LF (nude + CD4 with LF); and nude mice that received CD8 + cells from nTx mice immunized with LF (nude + CD8 with LF). Histology and serology were studied 3 months after transfer.

\section{Blood Chemistry}

Serum biochemistry, including amylase, gammaglutamyl transpeptidase, alanine aminotransferase, and glucose, were measured using a biochemical auto-analyzer for clinical use (Hitachi 7170; Hitachi, Ltd., Ibaragi, Japan). To evaluate humoral immunity to CA-II or LF, antibodies against CA-II or LF were measured with a solid phase ELISA. CA-II or LF $(50 \mu l$ of a $20 \mathrm{ng} / \mathrm{ml}$ solution) was coated onto 96-well microtiter plates (Corning Costar Corporation, Cambridge, Massachusetts). Normal BALB/c mouse serum served as controls. After overnight incubation at $4^{\circ} \mathrm{C}$, serially diluted mouse serum $(0.1 \mathrm{ml})$ was plated followed by incubation at room temperature for 1 hour. After washing the plate, horseradish peroxidase- 


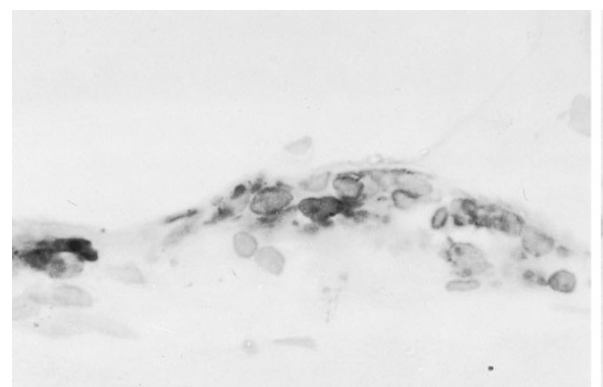

\section{a}
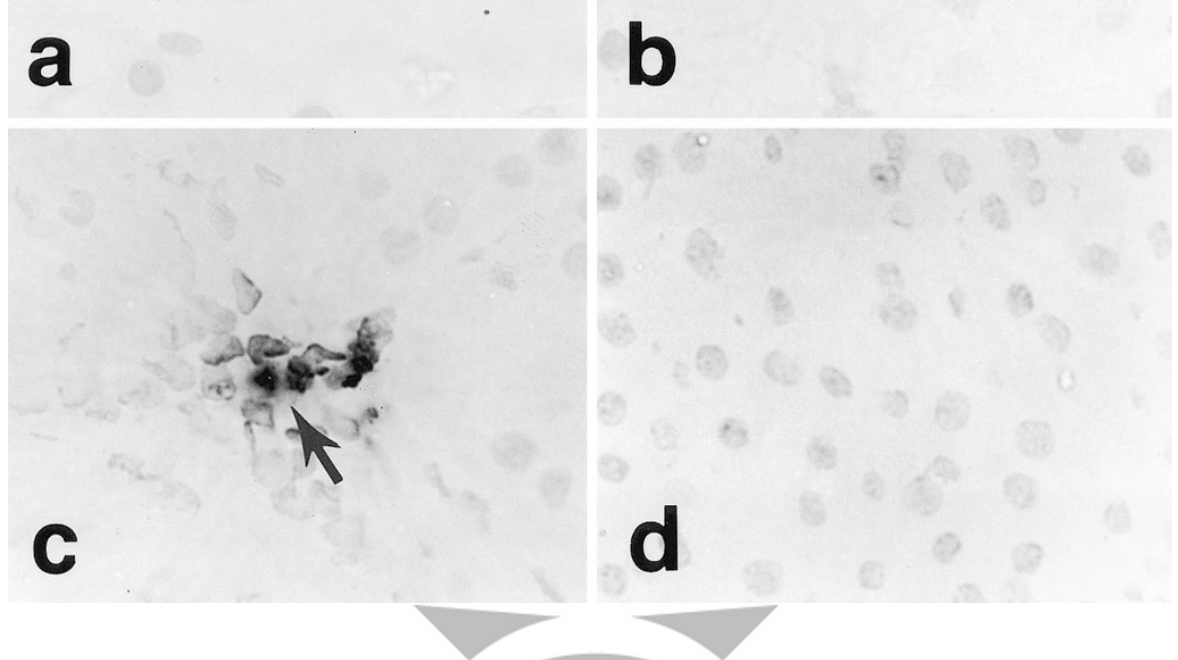

Figure 6.

Terminal deoxynucleotidyl transferase-mediated dUTP-biotin nick end-labeling (TUNEL) staining of the pancreas. Positive cells were observed in the pancreatic duct cells of the nude mice that received CD4 spleen cells from nTx mice immunized with CA-II (a). There were no positive cells in the negative control (b). c, Nude mice that received CD4+ spleen cells from the nTx mice immunized with LF. Acinar cells were positively stained (arrow). Infiltrating lymphocytes around these acinar cells were also positively stained. d, Control mice. There were similar results in nTx mice immunized with CA-II or LF and nude mice that received whole spleen cells prepared from nTx mice immunized with CA-II or LF (data not shown). Original magnification, $\times 800$.

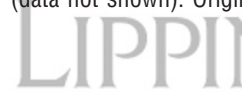

labeled goat anti-mouse immunoglobulin (Cappel Laboratories, Cochranville, Pennsylvania), diluted to a predetermined concentration, was added to each well. After 1 hour of incubation followed by rigorous washing, each well was reacted with a substrate (o-paraaminobenzidine) solution for 15 minutes. The reaction was terminated with $25 \mu \mathrm{l}$ of $2 \mathrm{M} \mathrm{H}_{2} \mathrm{SO}_{4}$ and the absorbency at $490 \mathrm{~nm}$ was determined using an enzyme-linked immunosorbent assay reader (Elx808; Bio-Tek Instruments, Highland Park, Vermont).

\section{Histology}

Pancreas, salivary glands, and liver were fixed with $4 \%$ phosphate-buffered formaldehyde $(\mathrm{pH} \mathrm{7.2)}$ and prepared for histologic examination. The sections were stained with hematoxylin and eosin and then evaluated independently by two pathologists who were blind to the origin of the specimens. To evaluate inflammatory activity, the degree of inflammation was scored into four categories according to those reported for an animal model of lupus nephritis and cholangitis: grade $0=$ no inflammation; grade $1=$ mild; grade 2 = moderate; or grade $3=$ severe). Each of these scores was then assigned a number $(0-3$, respectively) for statistical studies, similar to those reported for the animal model of lupus nephritis and cholangitis (Ueno et al, 1998; Watson et al, 1992).

\section{Immunohistochemistry}

Immunohistochemical staining was performed on freshly frozen sections using the avidin-biotin immunoperoxidase method. Briefly, freshly frozen sections were fixed in acetone for 10 minutes, rinsed in PBS $(\mathrm{pH}$ 7.2), and incubated with the appropriate blocking agent for 20 minutes. Biotin-conjugated rat antimouse B220, CD4, and CD8 (BD Pharmingen, San Diego, California) monoclonal antibodies were applied to the sections for 2 hours. The sections were washed with cold PBS for 30 minutes and incubated with avidin-biotin peroxidase complex (ABC) (Vector Laboratories, Inc., Burlingame, California) for 30 minutes. After washing with PBS, the sections were reacted with a fresh mixture of $0.05 \% 3,3^{\prime}$-diaminobenzidine and $0.005 \% \mathrm{H}_{2} \mathrm{O}_{2}$ in Tris-buffer $(0.05 \mathrm{M}, \mathrm{pH} 7.6)$ for 5 minutes and washed with distilled water. Controls were incubated with normal rat serum (Cappel Laboratories) instead of the monoclonal antibodies. These control samples produced negative results.

\section{In Situ End-Labeling of Fragmented DNA}

Fragmented DNA was studied using an in situ endlabeling technique with the commercially available TUNEL staining kit (ApopTag; Oncor, Gaithersburg, Maryland) as described previously (Anderson et al, 1997). Briefly, fresh frozen sections were fixed with 
(a)

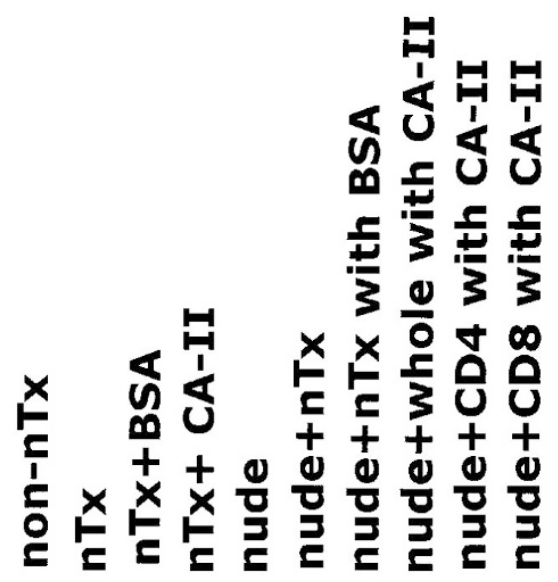

IF $\mathbf{N}-\gamma$

IL-4

G3PDH
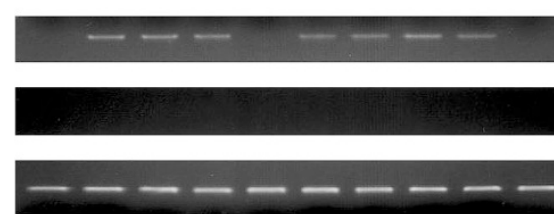

(b)

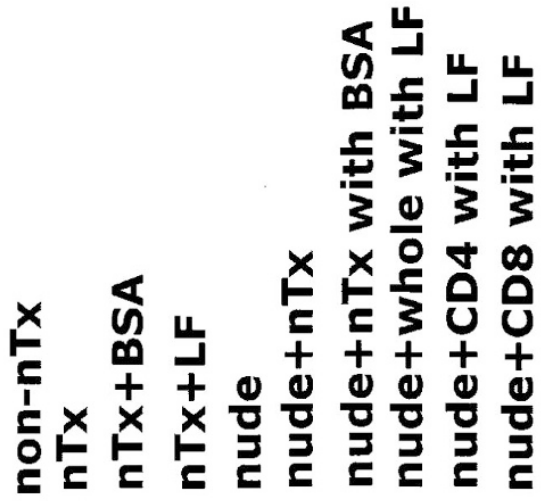

IF $\mathbf{N}-\gamma$

IL-4

G3PDH

Figure 7.

Gene expression of cytokines in the salivary glands determined using reverse transcription-polymerase chain reaction (RT-PCR). a, The mRNA of IFN- $\gamma$ was expressed in the salivary glands of $n T x$ mice, but was not significantly changed by immunization. Nude mice that received whole or CD4+ spleen cells from nTx mice immunized with CA-II also expressed the IFN- $\gamma$ message in the salivary glands. b, The mRNA of IFN- $\gamma$ was expressed in the salivary glands of nTx mice glands, and immunization with LF up-regulated IFN- $\gamma$ gene expression. Nude mice that received whole or CD4+ spleen cells from nTx-mice immunized with LF had an up-regulated IFN- $\gamma$ message compared with nude mice that received whole spleen cells from nonimmunized nTx mice or nTx mice immunized with BSA, whereas nude mice that received CD8 + spleen cells did not express the IFN- $\gamma$ gene. IL-4 mRNA was not expressed in any mice. Nonimmunized non-nTx, nonimmunized non-nTx BALB/c mice; nonimmunized $n T x$, nonimmunized $n T x$ BALB/c mice; $n T x+B S A, n T x$ mice immunized with BSA; $n T x$ + CA-II, $n T x$ mice immunized with CA-II; nude, untreated nude mice; nude $+\mathrm{nTx}$, nude mice that received whole spleen cells prepared from nonimmunized $\mathrm{nTx}$ mice; nude $+\mathrm{nTx}$ with $\mathrm{BSA}$, nude mice that received whole spleen cells prepared from $\mathrm{nTx}$ mice immunized with BSA; nude + $\mathrm{nTx}$ with CA-II, nude mice that received whole spleen cells from $\mathrm{nTx}$ mice immunized with CA-II; nude + CD4 with CA-II, nude mice that received CD4 + cells from $\mathrm{nTX}$ mice immunized with CA-II; nude + CD8 with CA-II, nude mice that received CD8 + cells from nTx mice immunized with CA-II; $n T x+L F, n T x$ mice immunized with LF; nude + whole with LF, nude mice that received whole spleen cells from nTx mice immunized with LF; nude + CD4 with LF, nude mice that received CD4 + cells from nTx mice immunized with LF; nude + CD8 + with LF, nude mice that received CD8 + cells from $\mathrm{nTx}$ mice immunized with LF.

$10 \%$ buffered formalin for 10 minutes at room temperature and washed three times with PBS. Digoxigeninlabeled dUTP was incorporated at the 3'-OH ends of the fragmented DNA by terminal deoxynucleotidyl transferase, anti-digoxigenin antibody conjugated with peroxidase was applied, and the peroxidase activity was revealed by treatment with 3-amino-9ethylcarbazol. Nuclei were lightly counterstained with methylgreen.

\section{Reverse Transcription-Polymerase Chain Reaction}

To analyze cytokine gene expression by RT-PCR, total RNA was extracted with the RNA extraction solution Isogen (Nippon Gene, Tokyo, Japan). RNA prepared from the pancreas was partially degraded. Therefore, we performed RT-PCR using the salivary glands, which had lesions similar to those of the pancreas. RNA was pooled from three murine salivary glands in each group. Total RNA was reverse-transcribed into DNA using the Super Script Preamplification System (Gibco BRL, Life Technologies, Inc., Rockville, Maryland). Total RNA in the reaction mixture was heated at $42^{\circ} \mathrm{C}$ for 50 minutes and at $70^{\circ} \mathrm{C}$ for another 15 minutes and then chilled on ice. PCR was performed with the following mouse-specific primers (Clontech, Palo Alto, California): IL-4: 5, 'CCAGCTAGTTGTCATC-
CTGCTCTCCПITCTCG and 3', CGTGGTACTTACTCAGGTTCAGGTGTAGTGAC; IFN- $\gamma$ : 5', TGCATCTTGGCTITGCAGCTCTTCCTCATGGC and 3', CGGTTCA AACTCCAGTTGTTGGTGTCCAGGT; Glyceraldehyde-3phosphate dehydrogenase (G3PDH): 5', GTGGGCCGCTCTAGGCACCAA and 3', CTCTTTGATGTCACGCACGATTTC.

The reaction mixture consisted of $20 \mu \mathrm{l}$ of $20 \mathrm{~mm}$ Tris- $\mathrm{HCl}(\mathrm{pH}$ 8.4), $50 \mathrm{~mm} \mathrm{KCl,} 2.5 \mathrm{~mm} \mathrm{MgCl} 2,200 \mathrm{~mm}$ each deoxy-nucleotide triphosphate (Perkin-Elmer, Branchburg, New Jersey), 50 pм of each specific primer, 1.0 U of Taq DNA polymerase (Ampli Taq Gold; Perkin-Elmer), and $1 \mu \mathrm{g}$ of the cDNA preparation. Amplification was performed with an automated thermal cycler (GeneAmp PCR System 9600R; PerkinElmer) for 35 cycles, each of which consisted of 20 seconds at $95^{\circ} \mathrm{C}$ for denaturing, 1 minute at $55^{\circ} \mathrm{C}$ for annealing, and 1 minute at $72^{\circ} \mathrm{C}$ for extension. The final cycle included a 10-minute extension step at $72^{\circ} \mathrm{C}$ to ensure full extension of the product. Each PCR product $(10 \mu \mathrm{l})$ was electrophoresed on a $2.0 \%$ agarose gel containing ethidium bromide, and the bands were examined using an image auto-analyzing system (Fotodyne, FOTOanalyst and Archive ECLIPSE; Advanced American Biotechnology, Fullerton, California). 


\section{Statistical Analysis}

All data are expressed as the mean \pm SD. Statistical analysis of the data was performed using a two-tailed Wilcoxon's $t$ test. A $p$ value of $<0.05$ was considered statistically significant.

\section{References}

Ainscough EW, Brode AM, and Plowman JE (1979). The chromium, manganese, cobalt and copper complexes of human lactoferrin. Inorg Chem Acta 33:149-153.

Anderson KM, Roshak A, Winkler JD, McCord M, and Marshall LA (1997). Cytosolic 85-kDa phospholipase A2mediated release of arachidonic acid is critical for proliferation of vascular smooth muscle cells. J Biol Chem 272: 30504-30511.

Asano M, Toda M, Sakaguchi N, and Sakaguchi S (1996). Auto-immune disease as a consequence of developmental abnormality of T cell subpopulation. J Exp Med 184:387-396.

Brock J (1995). Lactoferrin: A multifunctional immunoregulatory protein? Immunol Today 16:417-419.

Colomb E, Pianetta C, Estevenon JP, Guy O, Figarella C, and Sales H (1976). Lactoferrin in human pancreatitis. Immunohistological localization in normal and pathological pancreatic tissues. Digestion 14:242-249.

Demols A, Moine OL, Desalle F, Quertinmont E, Laethem JLV, and Deviere J (2000). CD4+ T cells play an important role in acute experimental pancreatitis in mice. Gastroenterology 118:582-590.

Ellison RT, Giehl TJ, and LaForce FM (1988). Damage of the outer membrane of enteric Gram-negative bacteria by lactoferrin and transferrin. Infect Immun 56:2774-2781.

Epstein O, Chapman EQG, Lake-Bakaar G, Foo AY, Rosalki SB, and Sherlock S (1982). The pancreas in primary biliary cirrhosis and primary sclerosing cholangitis. Gastroenterology 83:1177-1182.

Fedail SS, Harvey RF, Salomon PR, and Read AE (1978). Radioimmunoassay of lactoferrin in pancreatic juice as a test for pancreatic diseases. Lancet 1:181-182.

Fox, RI, Kang HI, Ando D, Abrams J, and Pisa E (1994). Cytokine mRNA expression in salivary gland biopsies of Sjögren syndrome. J Immunol 152:5532-5539.

Hahm KB, Im YH, Lee C, Parks WT, Bang YJ, Green JE, and Kim SJ (2000). Loss of TGF- $\beta$ signaling contributes to autoimmune pancreatitis. J Clin Invest 105:1057-1065.

Haneji N, Hamano H, Yanagi K, Higashiyama H, Saito I, Noji S, Sugio $H$, and Hayashi $Y$ (1998). Identification of $\alpha$-fodrin as a candidate autoantigen in primary Sjögren's syndrome. Science 276:604-607.

Hayakawa T, Harada H, Noda A, and Kondo T (1983). Lactoferrin in pure pancreatic juice in chronic pancreatitis. Am J Gastroenterol 78:222-224.

Hayashi Y, Haneji N, Hamano H, Yanagi K, Takahashi M, and Ishimaru N (1996). Effector mechanism of experimental autoimmune sialoadenitis in the mouse model for primary Sjögren's syndrome. Cell Immunol 171:217-225.

Horiuchi A, Kawa S, Akamatsu T, Aoki Y, Mukawa K, Furuya $\mathrm{N}$, Ochi $\mathrm{Y}$, and Kendo K (1998). Characteristic pancreatitic duct appearance in autoimmune chronic pancreatitis: A case report and review of the Japanese literature. Am J Gastroenterol 93:260-263.

Hunger R, Muller $\mathrm{CH}$, Zgraggen $\mathrm{K}$, Friess $\mathrm{H}$, and Buchker MW (1997). Cytotoxic cells are activated in cellular infiltrates of alcoholic chronic pancreatitis. Gastroenterology 112: 1656-1663.

Ito T, Nakano I, Koyanagi S, Miyahara T, Migita Y, Ogoshi K, Sakai H, Matsunaga S, Yasuda O, Sumii T, and Nawata H (1997). Autoimmune pancreatitis as a new clinical entity. Dig Dis Sci 42:1458-1468.

Itoh M, Takahashi T, Sakaguchi N, Kuniyasu Y, Shimizu J, Otsuka F, and Sakaguchi S (1999). Thymus and autoimmunity: Production of CD25+ CD4+ naturally anergic and suppressive $T$ cells as key function of the thymus in maintaining immunologic self-tolerance. J Immunol 162: 5317-5326.

Kamiyasu M, Watanabe Y, Miura T, Masuda K, Nakanishi T, Kaziyama G, and Gershwin ME (1997). Experimental hepatitis in neonatally thymectomized mice: Transfer of disease and role of T cells. Clin Immunol Immunopathol 83:302-309.

Katakai T, Mori K, Masuda T, and Shimizu A (1999). Differential localization of Th1 and Th2 cells in autoimmune gastritis. Int Immunol 10:1325-1334.

Keith RG, Keshavjee SH, and Kerenyi NR (1985). Neuropathology of chronic pancreatitis in humans. Can J Surg 28:207-211.

Kino-Ohsaki J, Nishimori I, Morita M, Okazaki K, Yamamoto Y, Onishi S, and Hollingsworth MA (1996). Serum antibodies to carbonic anhydrase I and II in patients with idiopathic pancreatitis and Sjögren's syndrome. Gastroenterology 110: 1579-1586.

Kojima A and Prehn RT (1981). Genetic susceptibility of postthymectomy autoimmune disease. Immunogenetics 14 : 15-27.

Kumpulainen T and Jalovaara P (1981). Immunohistochemical localization of carbonic anhydrase isoenzymes in the human pancreas. Gastroenterology 80:796-799.

Marth T, Trober W, and Kelsall BL (1996). High dose oral tolerance in ovalbumin TCR-transgenic mice: Systemic neutralization of IL-12 augments TGF-beta secretion and T cell apoptosis. J Immunol 157:2348-2357.

Masanaga T, Watanabe Y, Van de Water J, Leung PS, Nakanishi T, Kajiyama G, Reubner BH, Coppel RL, and Gershwin ME (1998). Induction and persistence of immunemediated cholangiohepatitis in neonatally thymectomized mice. Clin Immunol Immunopathol 89:141-149.

Miyauchi J (1984). Distribution and subcellular localization of lactoferrin in human tissues. Acta Histochem Cytochem 17:177-189.

Miyauchi $Y$ and Watanabe $Y$ (1987). Immunocytochemical localization of lactoferrin in human neutrophils. An ultrastructural and morphometrical study. Cell Tissue Res 247:249258.

Montefusco PP, Geiss AC, Bronzo RL, Randall S, Kahn E, and McKinley MJ (1984). Sclerosing cholangitis, chronic pancreatitis, and Sjögren's syndrome: A syndrome complex. Am J Surg 147:822-826.

Mustafa W, Zhu J, Deng G, Diab A, Link H, Frithiof L, and Klinge B (1998). Augmented levels of macrophage and Th1 cell-related cytokine mRNA in submandibular glands of MRL/ 
Ipr mice with autoimmune sialoadenitis. Clin Exp Immunol 112:389-396.

Nishimori I, Bratanova T, Toshkov I, Caffrey T, Mogaki M, Shibata Y, and Hollingsworth MA (1995). Induction of experimental autoimmune sialoadenitis by immunization of PL/J mice with carbonic anhydrase II. J Immunol 154:4865-4873.

Nishio A, Hosono M, Watanabe Y, Sakai M, Okuma M, and Masuda T (1994). A conserved epitope on $\mathrm{H}+/ \mathrm{K}+-$ adenosine-triphosphatase of parietal cells discerned by a murine gastritogenic T cell clone. Gastroenterology 107: 1408-1414.

Ohana M, Okazaki K, Haziro K, and Uchida K (1998). Antilactoferrin antibodies in autoimmune liver diseases. Am J Gastroenterol 93:1334-1339.

Okazaki K, Tamura S, Morita M, Nishimori I, Yamamoto Y, and Yamamoto $Y$ (1989). Interspecies crossreactive antigen of the pancreatic duct cell prepared by monoclonal antibody. Int J Pancreatol 5:359-377.

Okazaki K, Uchida K, Ohana M, Nakase H, Uose S, Inai M, Matsushima Y, Katamura K, Ohmori K, and Chiba T (2000). Autoimmune-related pancreatitis is associated with autoantibodies and Th1/Th2-type cellular immune response. Gastroenterology 118:1-10.

Peakman M and Vergani D (1997). Torelance and the mechanism of the autoimmunity. In: Basic and clinical immunology. London: Harcourt Brace Publisher International, 117130.

Peen E, Enestrom S, and Skogh T (1996). Distribution of lactoferrin and 60/65 kDa heat shock protein in normal and inflamed human intestine and liver. Gut 38:135-140.

Reitamo S, Konttinen YT, and Segerberg-Konttinen M (1980). Distribution of lactoferrin in human salivary gland. Histochemistry 66:285-291.

Saito K and Nakanuma Y (1992). Lactoferrin and lysozyme in the intrahepatic bile duct of normal livers and hepatolithiasis. J Hepatol 15:147-153.

Sakaguchi S, Fukuma K, Kuribayashi K, and Masuda T (1985). Organ-specific autoimmune diseases in mice by elimination of $T$ cell subset. I. Evidence for the active participation of $T$ cells in natural self-tolerance; deficit of a $T$ cell subset as a possible cause of autoimmune disease. $\mathrm{J}$ Exp Med 161:72-87.
Sarles H, Sarles JC, Camatte R, Muratore R, Gaini M, Guien C, Pastor J, and Roy F (1965). Observation on 205 confirmed cases of acute pancreatitis, and chronic pancreatitis. Gut 6:545-559.

Sarles H, Sarles JC, Muratore R, and Guien C (1961). Chronic inflammatory sclerosis of the pancreas an autonomous pancreatic disease? Am J Dig Dis 6:688-698.

Strand V and Talal N (1979). Advances in the diagnosis and concept of Sjögren's syndrome (autoimmune exocrinopathy). Bull Rheum Dis 30:1046-1052.

Tsubata R, Tsubata T, Hiai H, Shinkura R, Matsumoto R, Sumida $T$, Miyawaki S, Ishida $H$, Kumagai $S$, Nakao K, and Honjo T (1996). Autoimmune disease of exocrine organ immunodeficient model for Sjögren's syndrome. Eur J Immunol 26:2742-2748.

Uchida K, Okazaki K, Konishi Y, Ohana M, Takakuwa H, Haziro K, and Chiba T (2000). Clinical analysis autoimmunerelated pancreatitis. Am J Gastroenterol 95:2788-2794.

Ueno $\mathrm{Y}$, Ishii M, Takahashi S, Igarashi $\mathrm{T}$, Toyota $\mathrm{T}$, and LaRusso NF (1998). Different susceptibility of mice to immune-mediated cholangitis induced by immunization with carbonic anhydrase II. Lab Invest 78:629-637.

Vallance AB, Hewlett RB, Snider P, and Collins MS (1998). T cell-mediated exocrine pancreatic damage in major histocompatibility complex class II-deficient mice. Gastroenterology 115:978-987.

Wakabayashi T, Motoo Y, Kojima Y, Makino H, and Sawabu $N$ (1998). Chronic pancreatitis with diffuse irregular narrowing of the main pancreatic duct. Dig Dis Sci 43:2415-2425.

Watson ML, Rao JK, Gilkeson GS, Ruiz P, Eicher EM, Pisetsky DS, Matsuzawa A, Rochelle JM, and Seldin MF (1992). Genetic analysis of MRL-Ipr mice: Relationship of the Fas apoptosis gene to disease manifestations and renal disease-modifying loci. J Exp Med 176:1645-1656.

Yoshida K, Takeuchi T, Watanabe S, Shiratori K, and Hayashi N (1995). Chronic pancreatitis caused by autoimmune abnormality. Proposal of concept of autoimmune pancreatitis. Dig Dis Sci 40:1561-1568. 